\title{
Fault and the allocation of spare organs
}

\author{
Brian Smart Keele University
}

\section{Author's abstract}

This paper argues that rectificatory justice should supplement distributive justice in allocating priority of access to scarce medical resources. Where a patient is at fault for the scarcity of healthy organs a principle of restitution requires that she should give priority to the faultless. Such restitution is non-punitive, and is akin to reparation in civil law, not criminal law. However, it is doubtful whether such a principle can be fairly applied within the present culture of governmental complicity in cigarette advertising.

There has been much useful discussion over the allocation of spare resources between patients who are not at fault for the scarcity of healthy organs. The debate here has been over the criteria for the fair distribution of such resources. Should the choice between those who are to receive spare organs and those who are not to receive them be made by lot, by social usefulness, by quality adjusted life years (QALYS) or by appeal to the 'good innings' criterion (1)? For our present purposes I shall assume that we have an answer in the 'distributive justice criterion' (DJC). The DJC gives us an order of priority between innocent parties. The question is: should the DJC be restricted to allocations involving innocent parties or should it apply to those responsible for the scarcity too? Should the allocation of spare organs ignore all questions of fault, or should considerations of rectificatory justice enter when at least one of the patients in need is responsible for the scarcity? Rectificatory justice covers both punishment and reparation for wrongs, and in law is to be found both in the criminal and civil law, for example in torts and contract (2).

\section{Historical fault}

There are those who hold that the DJC should command all allocation simply on the ground that the question of responsibility never arises. Michael Lockwood, for example, expresses scepticism about

\section{Key words}

Fault; allocation; organs; restitution. free will: ‘.. we are all of us victims of our genetic $\stackrel{\sim}{\circ}$ inheritance, upbringing and so forth, and ... it is not $\overrightarrow{.}$ true that people who bring certain kinds of health $\tilde{\sigma}$ care need on themselves - for example by driving 을 dangerously, overeating, smoking or abusing drugs or alcohol - really could, in the final analysis, have 3 acted any differently' (3). This is not the place to discuss the issue of free will and responsibility. But, whether we believe in free will or not, we need to discuss its implications, and Lockwood has not $\stackrel{Ð}{\perp}$ addressed these. Our everyday practice of morality and law certainly does distinguish between people who are at fault and those who are not. The cloth out of which that everyday practice weaves culpability is made up of intention and foresight, knowledge of right and wrong, rationality, control over one's actions and emotions, beliefs about the circumstances of the action and a capacity to exercise reasonable care about others. For those who wish to reserve judgement on free will our question still stands: if a person is responsible for a shortage of healthy organs, should their access be $\dot{\sigma}$ determined wholly by distributive criteria or should 3 . rectificatory justice (punishment or reparation) be $\delta$ involved?

In a recent article proposing a complete criterion $ᄋ$ of allocation, Michael J Langford distinguishes between past fault, which his proposed criterion excludes as ground for allocation, and a present or future condition, for example alcoholism, which o could ground allocation 'if it rendered the medical $\tilde{O}$ prognosis poor' (4). However, he does not provide $\underset{\omega}{N}$ any reason why past fault should be excluded. Now for our purposes it may just be the case that 0 Langford has successfully delineated the DJC. $\frac{\mathrm{\Phi}}{\varnothing}$ Indeed, exclusion of historical fault would be $\stackrel{?}{+}$ definitionally required, for it would exclude 7 questions of rectificatory justice. But it would plainly beg the question arbitrarily to exclude rectificatory $\stackrel{\unrhd}{\Omega}$ criteria from a complete criterion of allocation: that $\stackrel{\mathbb{Q}}{\Omega}$ requires argument.

It is, however, possible to reconstruct a line of reasoning that may have influenced Langford. He응 believes that a principle of equality should govern his criterion, and, he claims 'that certainly looks like a $\frac{\bar{\alpha}}{\partial}$ deontological principle' (4), by which he means 'one? 
that relates to rights and duties that are alleged to apply regardless of the consequences' (5). However, it emerged that he is not defending a deontological principle since he is elaborating a principle to which deontologists, utilitarians (who are interested in only the consequences) and those uncommitted to an ethical theory may subscribe (4). But there is no such neutral principle. It is only utilitarianism which, at base, wholly rejects the moral significance of the past. It is only utilitarianism which would find no possible role for historical fault in a complete principle of allocation: deontology and ordinary morality commonly base judgements of desert, entitlement and liability on past fault of one of the parties involved.

It might also be the case that Langford believes that including rectificatory criteria turns scarce resource allocation into punishment. To that argument I now turn.

\section{A non-punitive principle of restitution}

The idea that historical fault should play a key role in the allocation of health care is vigorously rejected by John Harris. He writes:

'We all, of course, have a duty to encourage and promote morality, but to do so by choosing between candidates for treatment on moral grounds is to arrogate to ourselves not simply the promotion of morality but the punishment of immorality. And to choose to let one person rather than another die on the grounds of some moral defect in their behaviour or character is to take upon ourselves the right not simply to punish, but capitally to punish, offenders against morality' (6).

We need to distinguish here between at least two different ways of choosing between people for treatment on moral grounds. The first way is where we give preference to one on grounds of her superior moral character or behaviour, but where neither party is in any way responsible for the scarcity of resources. To decide in this way is to include morality in the DJC: it is not addressed to rectifying any wrong, for the problem of scarcity is neither party's fault. Harris may be right not to include morality in the DJC, but that is another matter. The second way of choosing between people for treatment on moral grounds is where the need to choose is the fault of one of the parties in need of treatment. However, the most obvious cases of such choices are not cases of punishment at all, but cases of self-defence and other-defence.

Consider a case of other-defence in which an unprovoked attack has been launched on Kurt by Charles. Kurt cannot retreat or restrain Charles but you have the power, at no risk to yourself, of intervening by killing Charles. Suppose you do this on the ground that Charles is at fault for causing the dilemma. There is a scarcity of resources, since you do not have the power to save both Kurt and Charles, only the power to save either Kurt or Charles. A just case of other-defence would be one in which you choose between these two on moral grounds, not on grounds of general character blemishes but on the ground that Charles is at fault for causing the scarcity of resources and so should bear the cost. This ground needs elaboration. Kurt is not at fault, and so not only should he not have to bear the cost, but Charles should be forced to make restitution to Kurt: in other words, Charles should be forced to restore Kurt to the position he rightfully enjoyed before Charles's attack endangered his life (7).

Here we have all the ingredients of a preferential choice between lives on moral grounds. But does it constitute the punishment of immorality, or, in this case, capital punishment? I suggest not. First of all, there is no account of punishment which licenses the treatment justified by self-defence. If Charles is killed for launching an unsuccessful attempt on Kurt's life, that is not because it is a suitable punishment but because it is the minimal reasonable force to defend Kurt: as punishment it would exceed even the harsh limits imposed by the lex talionis (an eye for an eye ...). If all that was needed to defend Kurt was for you to give Charles a slap on the cheek or a harsh frown then that would hardly be a punishment to fit the crime of attempted murder, but it would be all that would be licensed by other-defence. In cases of self-defence and other-defence where the aggressor survives, we can distinguish more clearly between the treatment licensed by defence and the treatment licensed by punishment: the question of punishment obviously does arise in cases of unsuccessful murder even when the aggressor has received the harm that was minimally necessary for a successful defence of the victim.

\section{Self-inflicted harm is not a crime}

A second reason for rejecting preferential treatment as punishment lies in the fact that self-inflicted harm is not a crime. Damaging one's own heart or lungs by smoking is not forbidden by law: it would be legal paternalism if it were. So the justification, if there is one, for discriminating against a smoker when only one healthy spare set of heart and lungs is available must be non-punitive. And that justification lies in restitution. For suppose that what the smoker who is at fault must do is to restore to others what was rightfully theirs before the commission of the fault. True, the smoker has inflicted harm on only himself. But this ceases to be true if he does not forfeit equality of entitlement to a spare set of heart and lungs. For example, if there is no forfeiture of equality then, the one non-smoker in need of a transplant has a $1 / 2$ chance of acquiring the spare set 
rather than a $1 / 1$ chance. Without differential treatment according to fault the non-smoker would be denied his rightful opportunity. By forfeiting his own right to equality the smoker restores the nonsmoker to her rightful status quo.

Interestingly, much of this argument applies to someone who damages another's healthy heart or who vandalises one of the two healthy spare sets of organs available (8). The obvious difference is that a crime has now been committed - harm to the person or damage to property: punishment is a matter for the criminal courts. But, in addition to the crime, we have the same kind of situation that arose with selfinflicted harm: there is a scarcity of resources. By harming another's heart, or by vandalising a spare set of organs on their way to the theatre, the person at fault has forfeited his right to equal priority with the innocent patient. The innocent patient is owed restitution of his $1 / 1$ chance of access to healthy organs that he possessed before the fault occurred. Restitution and reparation is a matter either for the civil courts or may be settled out of court.

It might be thought that self- and other-defence are sufficiently unlike choice between lives caused by a shortage of resources to provide a useful insight into the nature of that choice. After all, self- and other-defence involve an aggressor who is a current threat to the victim. For this reason, Langford's distinction between historical fault and current condition might explain why he could justify selfand other-defence. And it might also explain why Harris might want to assimilate preferential treatment against a patient at fault to punishment: for it would involve an historical and not an ongoing fault.

\section{The threat may be current}

But historical fault may be found in self-defence. The threat may be current, but the fault may be historical (9). Imagine the aggressor has pushed his trolley to the crest of the hill and has now tied himself in it so that he cannot jump out: you are tied to the track down which the trolley is heading and fortunately you can operate by remote control a bulldozer which, at the flick of the switch, will straddle the track, protect you but kill the aggressor when his trolley smashes into it. The fault is historical in the sense that after the trolley has crested the hill, the aggressor can do nothing more about it, and flight or effective threats are not open to the victim. This is unlike the current fault of an aggressor who is trying to strangle you and in whose power it is to desist right up to the moment of the victim's death. In this case both the threat and the fault are current. But the burden of restitution is the same in both cases. Indeed, it is not inappropriate to ask, in the present tense, 'Who is responsible?' in both cases of historical and current fault.
We now have a non-punitive principle of restitution. It properly belongs to rectificatory, not distributive justice, since it requires those at fault to restore those endangered or harmed to their rightful status quo. It is not punishment, since it is like paying damages in a civil libel suit.

\section{Priority of non-smokers over smokers in access to spare organs?}

What are the implications of this principle of restitution? Should medical practitioners supplement the DJC with a fault criterion that prioritises the innocent? Notoriously in ethics, as in economics and physics, there is a large gap between the $\tilde{\sim}$ enunciation of a sound principle and its practical application.

First of all, it is unclear who should apply the DJC supplemented by a rule of restitution. We have ruled out criminal courts since forfeiting priority of access to scarce resources is not a matter for punishment. But the application of the principle does introduce a dimension not covered by the DJC: assessing degrees of culpability. So expertise for assessing fault is required on any panel that is involved in the allocation: assessing fault is not a medical skill. It is to be hoped that the composition of any panel would, like juries, introduce more democracy and in some way involve consultation with those needing a transplant or with their representatives. One crucial reason for this is that if restitution is owed to another party, it does not follow that the restitution has to be made. For it is always open to the person who has the right to restitution to waive that right. This is not peculiar to debts of restitution, but a more general feature of obligations. After all, I do not have to pay you back the $£ 10$ I promised to repay you if you waive your right to repayment. You are morally sovereign over whether I will be held to that promise or not.

If, as law and ordinary morality suggests, it is an empirical matter whether individuals are at fault, there are undoubtedly difficulties in identifying particular cases. For example, the problem with $\mathcal{N}$ many cases of self-inflicted heart or lung disease is $N$ that it may be caused by addiction to nicotine. Addiction as such does not rule out fault. For someone may have taken up smoking or drinking quite freely, but foreseen that he would not be able to give it up once he was addicted (10). On the other hand, a large proportion of smokers become addicted in their early teens and so, because of immaturity, are not responsible for their addiction. Nor should we ignore the stress-related conditions that might cause much smoking in adults: unemployment, inability to keep up mortgage repayments and broken relationships are familiar of examples of such causes. Fault is either negated or much reduced by such causes. But it would be a mistake to exaggerate the difficulties of assessing? 
culpability. Let us grant that many complex cases are impossible to resolve and that many others may be resolvable only by the rarified skills of trained lawyers. Because of the constraints of time such cases would be beyond the scope of the allocation of scarce medical resources. Such cases may be contrasted with those in which the relevant histories of the parties are known and which present good, and non-conflicting, evidence of the culpability of one of them. We would insist on this if other-defence were to be justified.

We must now distinguish between being responsible for a condition and being at fault or culpable for that condition arising. For there to be a fault there must be a wrong committed as well as there being responsibility for that wrong. A miner or fireman chooses freely to subject himself to greater risk of harm or disease than is met with in most occupations. And, on the special assumption that if he were not to make that choice nobody would fill his place, it may be true that he causes a shortfall in spare healthy organs. But, because of the social value placed upon such occupations, we are not tempted to say that such a shortfall is the fault of the miner or the fireman. Since there is no fault there can be no case for saying that miners should have less priority than those who have no responsibility for their condition. But why should the social value of the occupations involving these risks mean that no fault occurs? The justification lies in fairness. In this case the value is one of social need: the society needs firemen and miners for its welfare. To ask people to take an extra risk (which may be rewarded by danger money) and then to give them lower medical priority than any ordinary member of the public would simply be unfair: indeed there is a case for giving them a higher medical priority in addition to danger money.

One qualification should be made here. The society asks people in dangerous occupations to take only the risks that are reasonable in the circumstances. Negligence can incur harm that was reasonably avoidable. Society did not ask the miner to harm himself in that way.

\section{Dangerous sports}

Dangerous sports such as rock-climbing and paragliding are not pursued out of social necessity since they do not contribute to social welfare. Society does not ask people to engage in rock-climbing or paragliding. If people freely engage in these sports should they not pay all the extra costs such activities risk and so receive a lower priority in access to spare organs? The argument with smoking is that it is unfair to spread the extra risks of this self-indulgence to those who prefer not to impose an extra risk on themselves. Should not the same apply to dangerous sports? A strong case can be made here for the social value of such sports, providing they are not too dangerous, and providing they are practised nonnegligently. The value does not belong to social welfare, it is not socially necessary as has been stated. But these sports do enhance lives as well as endanger them. Their value is both intrinsic and extrinsic. Intrinsically, skills of a very high order can be acquired, with an accompanying feeling of achievement; but even beginners find the activity exciting and challenging. Yet it is also a spectator sport, in the sense that it can be followed with binoculars or cameras and be read about. Extrinsically, the activity is character-forming as well as being able to provide the best exponents with a living. Activities of this kind thus become a part of our culture and their value contributes to a worthwhile life. After all, social welfare is not an end in itself: it simply enables us to choose and pursue a worthwhile life.

\section{Moral complicity}

Do dangerous sports differ in important respects from smoking or hard drinking? I think it is easy to show that our society delivers a mixed message on this issue. On the one hand, it permits advertising and sponsorship which may target children, and which presents smoking and drinking as appendages to a glamorous life-style. And, on the whole, it does not restrict smoking very seriously in public places, even when the dangers of passive smoking are well known. Such a policy seems to countenance the sharing of risks between smokers and the general public. On the other hand, government health warnings are compulsory on packets and advertisements. I think the upshot of this is that our society may be charged with moral complicity in the tobacco companies' operations and in the smokers' selfinfliction of harm. Part of the message is that there is no fault: the other part of the message is that the activity is dangerous. When combined, these messages are compatible with the claim that smoking is a valuable (chic, cool) way of living in which it would be fair that we should all, smokers and non-smokers alike, bear the costs equally in the case of access to medical care: it would be unjust if non-smokers were given priority.

The claim that smoking is socially valuable should be challenged. One familiar way of doing this is to point out that its value is an illusion created by advertisers, an illusion which can affect young people at an impressionable and vulnerable phase in their lives. We have remarked on how it can be seen as a part of stylish living: this claim might be sustainable if we could substitute a substance that had no deleterious effects on our health. But in the light of its probable effects, the illusion can be sustained only by screening off or ignoring those probable effects. Also, safer remedies are available for removing the stress that smoking can remove (for example exercise or alcohol in moderate quantities). It may be rightly claimed that smoking causes private 
pleasure while not harming anyone else if practised privately. But that is a reason why people's right to smoke in private should be defended, provided they are aware of the risks. It is not a reason why those risks should be shared with the general public and so reduced for the participants themselves: if the activity lacks social value then the risks should be borne by the participants alone.

So far as smoking is concerned this paper is deliberately hedged about with qualifications. A society which banned the advertising of tobacco and attached no social value to smoking would share no fault with those who smoked of their own free will. In such circumstances, it would be fair to give a lower priority to smokers in the allocation of spare organs.

The argument for this conclusion has been deontological and has been based on a principle of restitution for an historical fault. Yet deontological thinking is only part of our moral thought: we must be sensitive to the consequences of our actions. It is therefore worth remarking that it is likely that the consequences of introducing a restitutive principle would be beneficial. Now that might appear doubtful if we consider Michael Lockwood's observation about one likely consequence of adopting a rule of priority according to fault:

'... there might be good welfarist reasons for according the claims of [smokers] on health care resources a relatively low priority, if the fact were to be widely publicized and could act as an effective deterrent to such irresponsible behaviour. But I doubt whether it would. Someone who is undeterred by the prospect of seriously damaging his health is hardly likely, in my opinion, to be deterred by the prospect of less than ideal health care thereafter' (11).

Lockwood may be right about this particular consequence, at least in the vast majority of cases. Few are likely to be made more responsible by a rectificatory response to their fault. But he ignores the possibility that a system of equal access for all alike might induce many to become more irresponsible about their health. This is a phenomenon that occurs in the field of safety measures (12). For example, if seat-belts are made compulsory there is a tendency for drivers to drive faster and so restore the former突 accident rates.

To conclude: rectificatory but non-punitive $\overrightarrow{\vec{G}}$ justice has in principle a role to play in the allocation of scarce medical resources. However, this would be음 just only within a framework of robust preventive $\overline{\bar{c}}$. medicine: this would mean effective health $\vec{\nabla}$ education and the elimination of cigarette advertising and sponsorship.

Brian Smart, $B A, P h D$, is a Lecturer in Philosophy in $\overrightarrow{\vec{F}}$ the Department of Philosophy at Keele University, ${ }_{\mathscr{N}}$ Staffordshire.

\section{References and notes}

(1) For the most recent account of a sophisticated allocative criterion see Langford $\mathrm{M} \mathrm{J}$. Who should get음 the kidney machine? Fournal of medical ethics 1992; 18:12-17.

(2) For the introduction of this distinction see Aristotle, The Nicomachean ethics bk 5: 1130a 22-1132a 27.

(3) Lockwood M. Quality of life and resource allocation. $\overrightarrow{0}$ In: Bell J M, Mendus S, eds. Philosophy and medicale welfare. Royal Institute of Philosophy, Lecture Series. 23. Cambridge: Cambridge University Press, 1988: 49.

(4) See reference (1) 13.

(5) See reference (1) 16.

(6) Harris J. The value of life. London: Routledge and Kegan Paul, 1985: 108.

(7) For a detailed account see Smart B J. Understandingo and justifying self-defence. International journal of $\bar{B}$ moral and social studies 1989; 4, 3: 231-244.

(8) For such a hypothetical see Wasserman D. Justifying self-defense. Philosophy and public affairs 1987; 16, 4: 367 , fn 29.

(9) David Wasserman wrongly attempts to dissociate ano aggressor from his current threat where the fault is historical and the point of no return has been? passed. See reference (8) 371-372. For a fault principle characterised as distributive rather than retributive or restitutive see Montague $P$. The morality of self-defense. Philosophy and public affair $\frac{D}{2}$ $1989 ; 18,1: 88$.

(10) See reference (2): bk 3: 1114a 15-21.

(11) See reference (3): 49 .

(12) See Trammell R L et al. Utility and survival. 0 Philosophy 1977; 52: 336. 